\title{
الاصلاح الاداري وعلاقته بالاجهاد الوظيفي لتدريسي كليات التربية البلنية وعلوم الرياضة
}

\author{
م.م. ليلى عبدالامير إبراهيم أ.م.د. سندس موسى جواد
}

كلية التربية البذنية وعلوم الرياضية للبنات-جامعة بغداد كلية التربية البذنية وعلوم الرياضية للبنات-جامعة بغداد sondus@copew.uobagdad.edu.iq

(00964) 07709813320

Rawan.alazzawi97@gmail.com

(00964) 077042898558

$$
\begin{aligned}
& \text { أ.د. منال عبود العنبكي } \\
& \text { كلية التربية البدنية وعلوم الرياضية للبنات-جامعة بغداد } \\
& \text { manal@copew.uobaghdad.edu.iq } \\
& \text { (00964) } 07816773376 \\
& \text { مستخلص البحث باللغة العربية }
\end{aligned}
$$

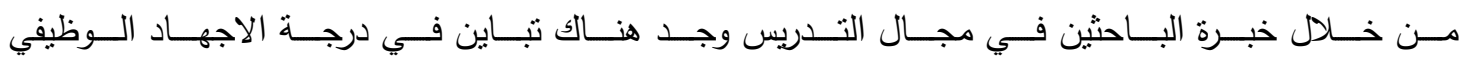

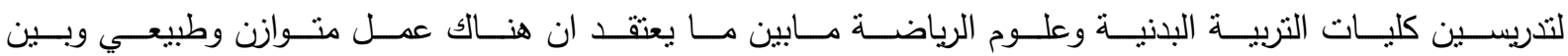

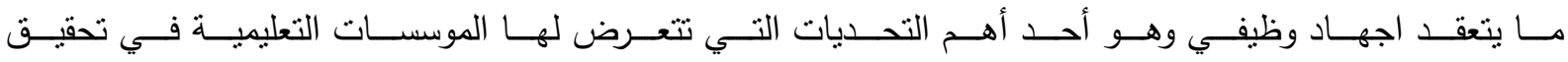

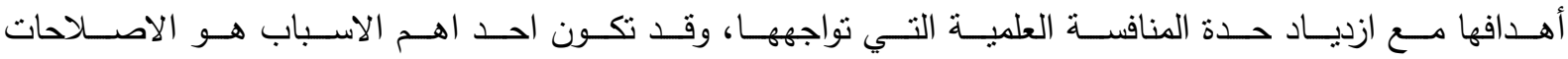

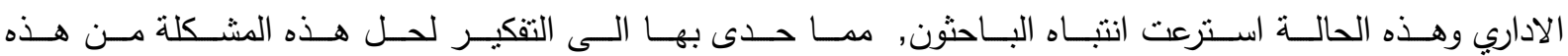

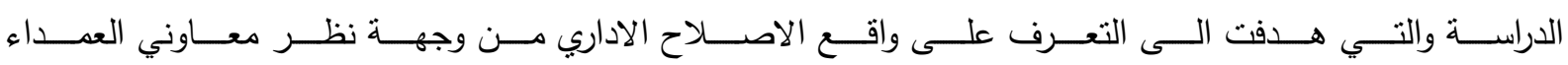

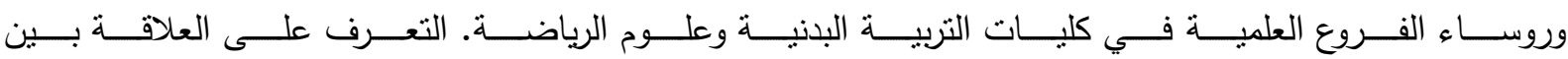

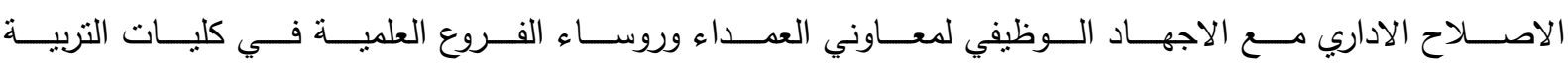

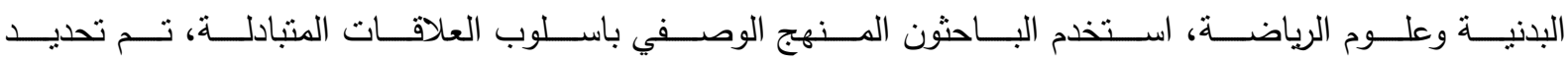

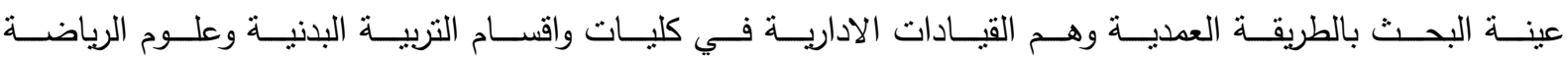

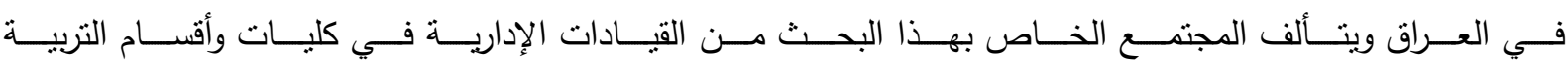

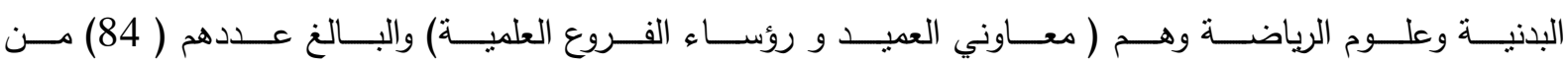

$$
\begin{aligned}
& \text { القيادات الادارية في كليات واقسام التربية البدنية وعلوم الرياضة في العراق. } \\
& \text { الكلمات المفتاحية: الاصلاح الاداري، الاجهاد الوظيفي، تدريسي، وعلوم الرياضة. }
\end{aligned}
$$

\section{ABSTRACT \\ Administrative Reform and Its Relationship with Occupational Stress In Physical Education and Sport Sciences' Faculty Members Lyla Abdul Ameer Asst. Prof. Dr. Sundos Musa Prof. Dr. Menal Abood College of Physical Education and Sport Sciences for Women}

The research aimed at identifying the reality of administrative reform from assisting deans and head of departments' point of view as well as identifying the relations between administrative reform and occupational stress reform from assisting deans and head of departments' point of view. The researchers used the descriptive method on (84) administrative leaders including assisting deans and head of departments in colleges and departments of physical education and sport sciences' colleges.

Keywords: Administrative reform, occupational stress, members of faculty, sport sciences. 


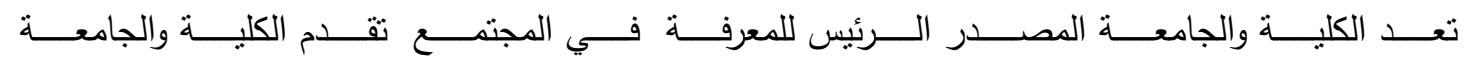

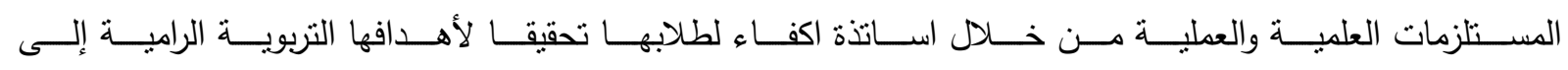

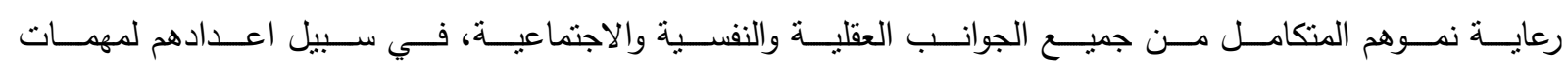

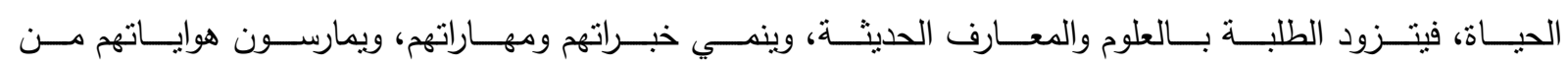

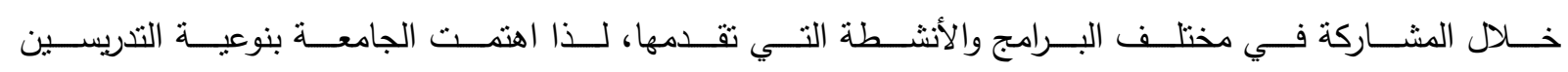

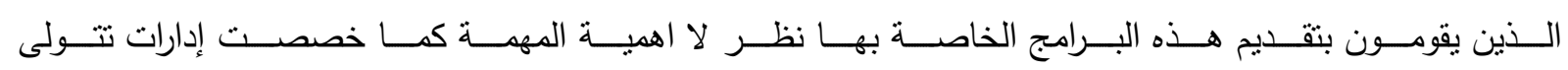

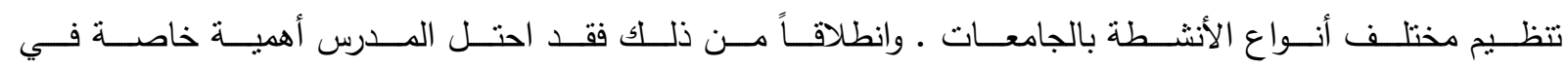
من اجل تتفيذ مهامه.

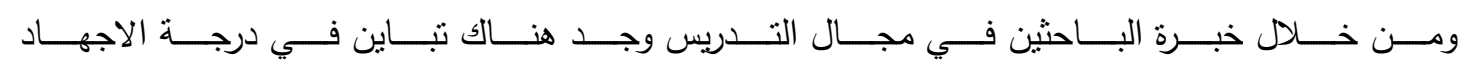

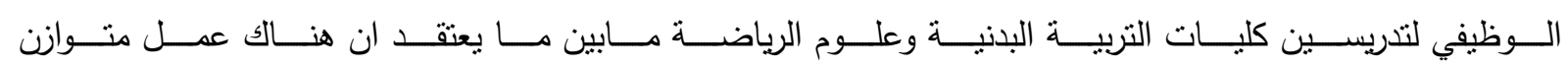

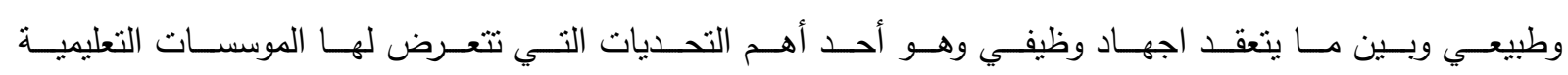

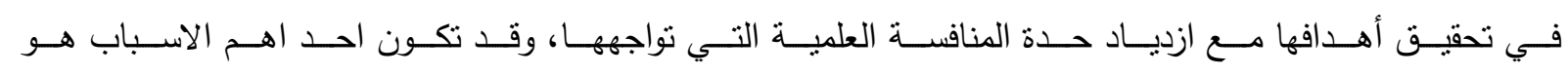

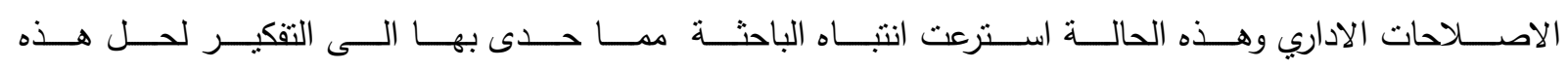

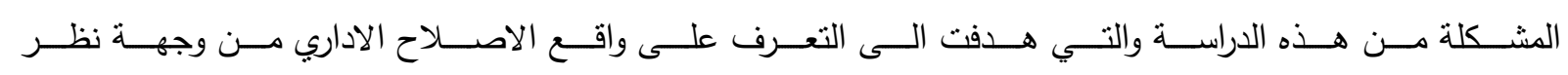

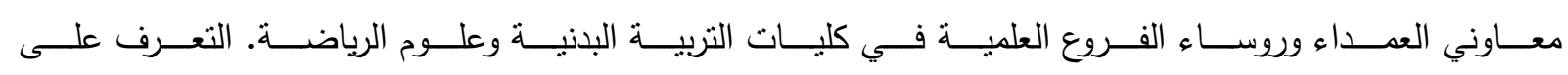

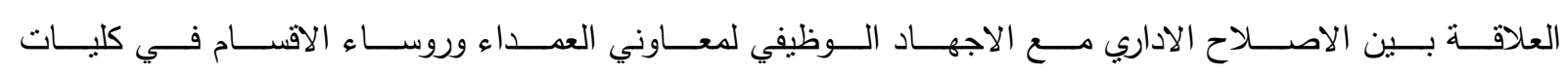
التربية البدنية وعلوم الرياضة.

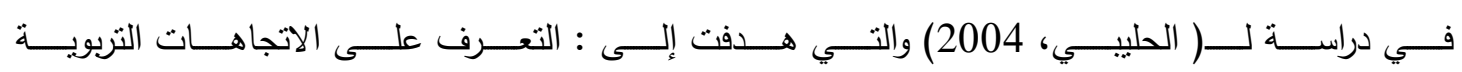

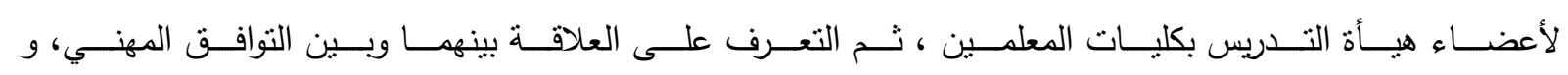

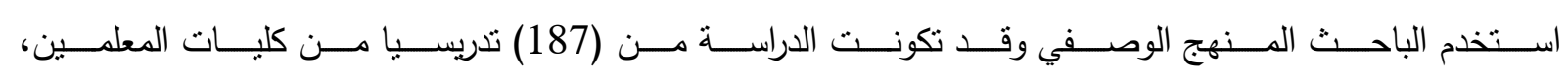

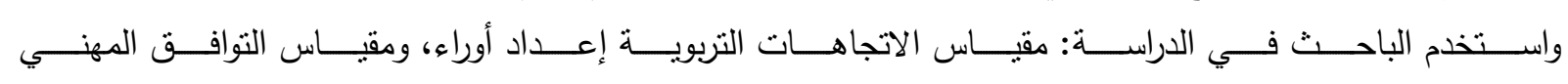
إعداد مصطفى خليل .

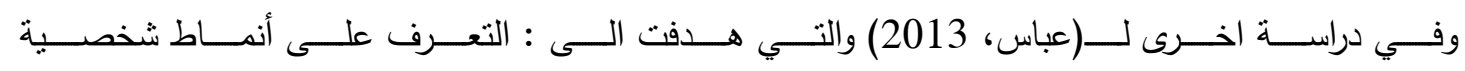

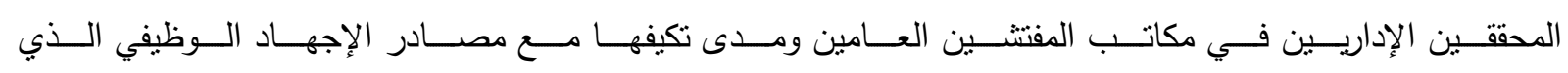

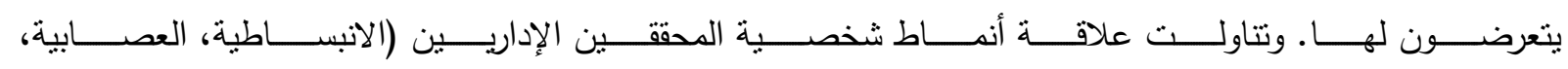

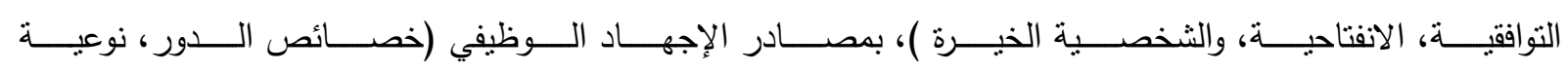

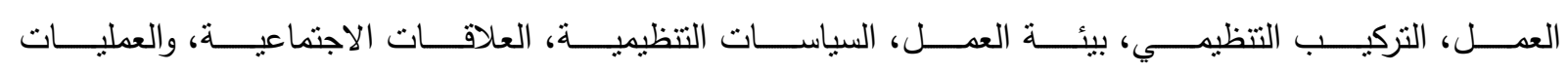
التتظيمية ) الذي يتعرضون له في العمل بمكاتب المفتشين العامين.

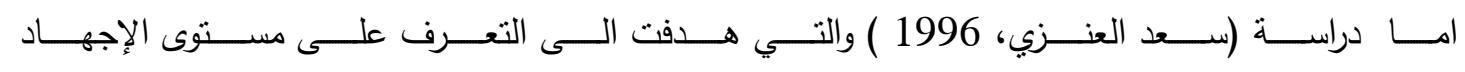

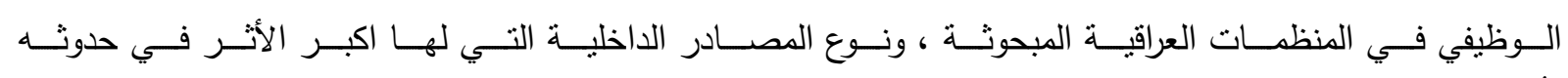

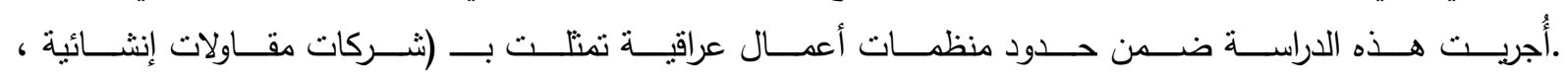

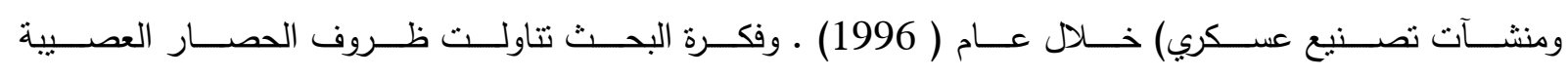

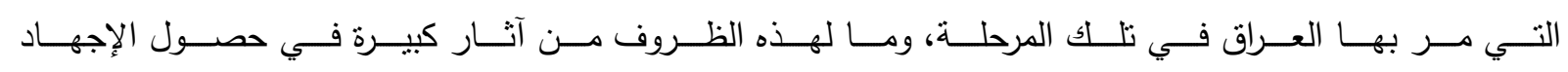

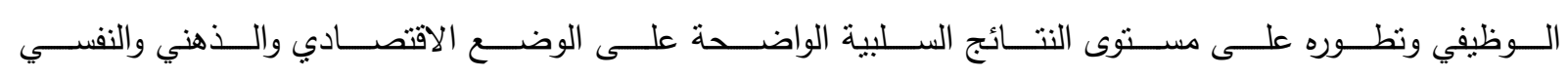
والبدني والسلوكي اتبع البحث المنهج الوصفي. 


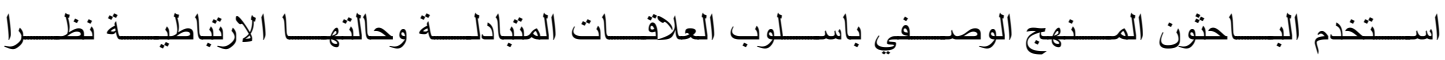

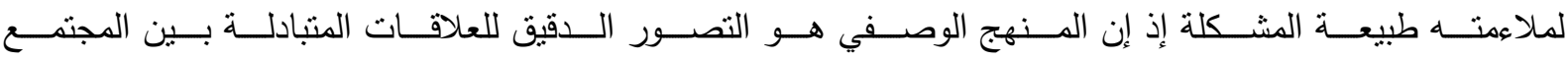

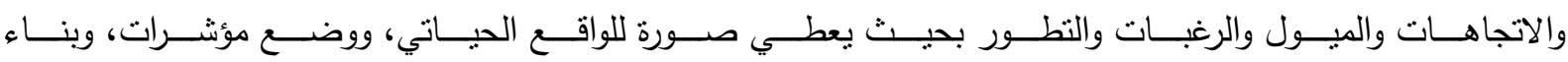
تتبؤات مستقبلية. (محجوب ، 2002، صفحة 263).

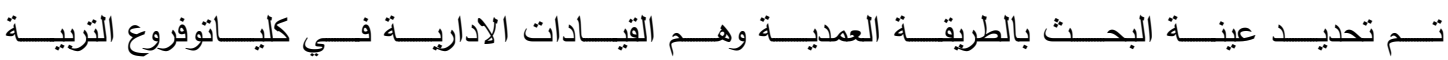

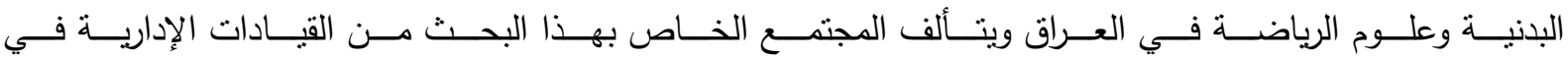

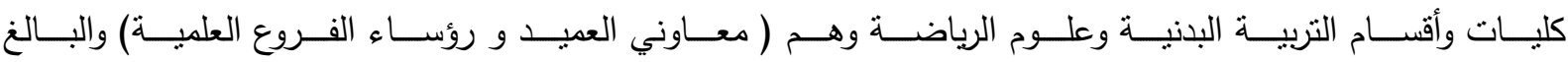
عددهم ( 84) من القيادات الادارية في كليات واقسام التربية البدنية وعلوم الرياضة في العراق.

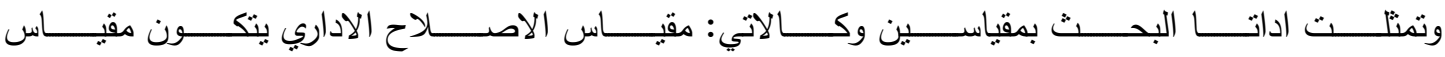

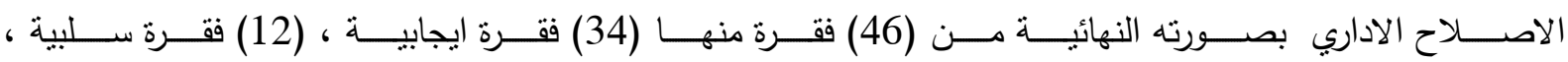

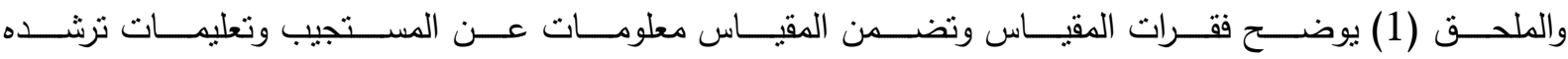

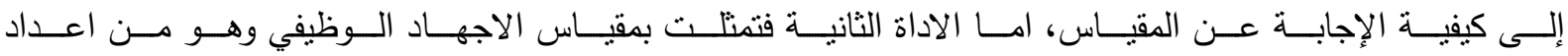

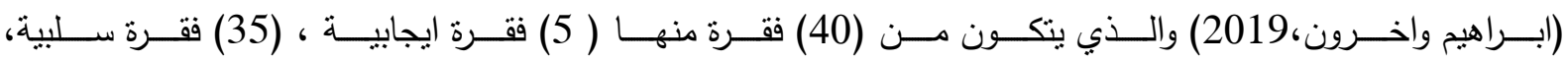
والملحق (2) يوضح فقرات المقياس.

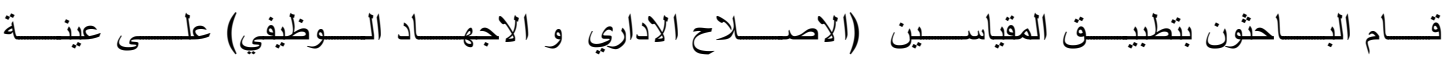

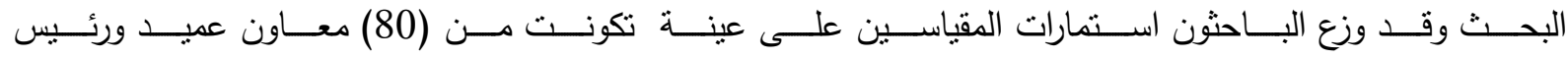

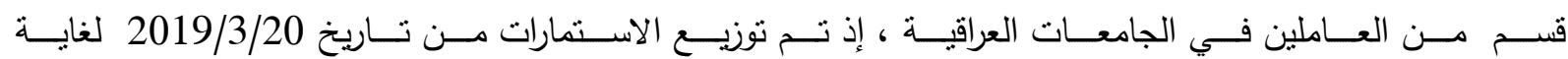
(2019/4/27 2019 وعولجت إحصائيا لاستخراج النتائج.

النتائج: جدول (1) نتائج الاختبار التائي لعينة واحدة لمعرفة دلالة مستوى لمقياس الاصلاح الاداري لعينة البحث وفقا لمحاور المقياس

\begin{tabular}{|c|c|c|c|c|c|c|c|c|c|c|}
\hline المستوى & الدلالة & sig & قيمة T & الفرضي & المعتوسط & الالحعراف & الالاهبية & الحسابي & الدرجة & مجال \\
\hline متوسط & معنوي & 0.044 & 2.049 & 33 & 0.695 & 6.221 & $\% 25.8$ & 3.129 & 34.42 & ادارة التغيير \\
\hline متوسط & عثوائي & 0.882 & 0.149 & 21 & 0.504 & 4.516 & $\% 15.1$ & 2.989 & 20.92 & المعرفية \\
\hline متوسط & معنوي & 0.002 & 3.199 & 30 & 0.885 & 7.653 & $\% 20.4$ & 2.726 & 27.26 & التمكين \\
\hline متوسط & عشوائي & 0.145 & 1.470 & 27 & 0.697 & 6.235 & $\% 19.5$ & 2.886 & 25.97 & الاستراتيجي \\
\hline متوسط & معنوي & 0.000 & 3.676 & 27 & 0.669 & 5.991 & $\% 18.4$ & 2.726 & 24.53 & الاداري \\
\hline متوسط & معنوي & 0.009 & 2.699 & 138 & 1.806 & 16.156 & & 2.894 & 133.1 & الاداريلاح \\
\hline
\end{tabular}


مجلة كلية التربية الرياضية / جامعة بغداد ** المجلد الحادي والثلاثون** العدد الثالث ** 2019.

جدول (2) عرض نتائج المتوسطات الحسابية والانحرافات المعيارية والنسبة المئوية والرتبة والمستوى لدرجات استجابات

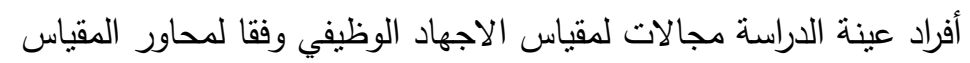

\begin{tabular}{|c|c|c|c|c|c|c|c|c|c|c|}
\hline المستوى & الدلالة & sig & قيمة T T & الفرضي & خطأ المتوسط & الالمعراف & الالهبية & الحستوسط & الارجة & مجال \\
\hline متوسط & معنوي & 0.000 & 5.77 & 24 & 0.45 & 0.486 & $\% 19.7$ & 2.675 & 21.40 & خصائص الدور \\
\hline متوسط & معنوي & 0.000 & 6.94 & 27 & 0.44 & 1.303 & $\% 22$ & 2.658 & 23.925 & العملية \\
\hline متوسط & عشوائي & 0.722 & 0.35 & 33 & 0.49 & 0.077 & $\% 21.3$ & 2.984 & 32.825 & التنظيم \\
\hline مقبول & معنوي & 0.000 & 10.99 & 21 & 0.45 & 0.539 & $\% 14.7$ & 2.28 & 16.01 & بيئة العمل \\
\hline متوسط & عشوائي & 0.059 & 1.91 & 15 & 0.30 & 0.351 & $\% 13.2$ & 2.882 & 14.412 & الاجتماعية \\
\hline متوسط & معنوي & 0.000 & 11.45 & 120 & 0.99 & 0.954 & & 2.714 & 108.575 & الوظيفي \\
\hline
\end{tabular}

جدول (3) يبين علاقة الارتباط بين الاصداح الاداري للمحاور الخمس مع مستوى الاجهاد الوظيفي

\begin{tabular}{|c|c|c|c|c|}
\hline \multirow{3}{*}{ معنوي } & \multicolumn{2}{|c|}{ الاجهاد الوظيفي } & \multirow{2}{*}{ التمكين الاداري } & \multirow[b]{2}{*}{ 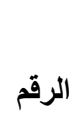 } \\
\hline & \multicolumn{2}{|c|}{ معامل الارتباط مستوى ألخطا } & & \\
\hline & 0,003 & -0.269 & ادارة التغير & 1 \\
\hline عشوائي & 0,094 & 0.148 & الثقافة المعرفية & 2 \\
\hline مغنوي & $\mathbf{0 , 0 3 4}$ & -0.236 & التمكين & $\overline{3}$ \\
\hline معنوي & 0,044 & -0.225 & التخطيط الاستراتيجي & 4 \\
\hline معنوي & 0.000 & -0.416 & التوافق الاداريةة & 5 \\
\hline 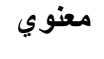 & 0.000 & -0.338 & للاح الإداري & \\
\hline
\end{tabular}

\section{المناقثةة:}

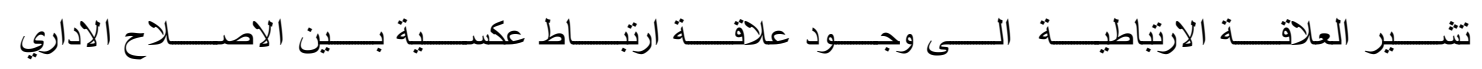

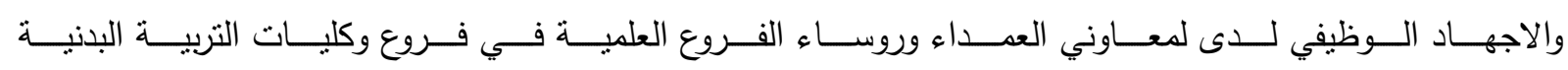

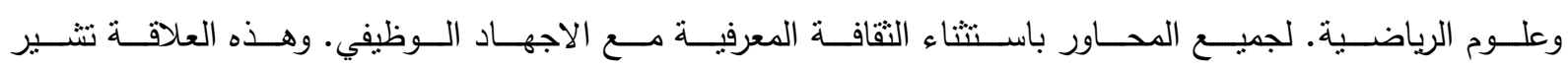

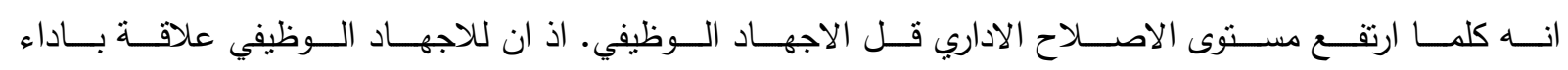

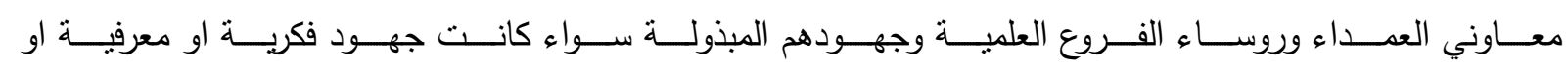

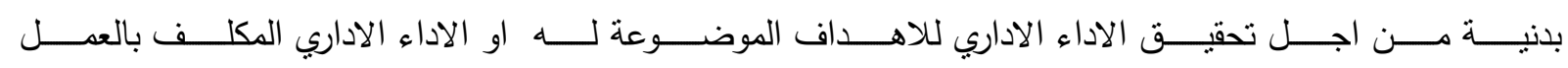

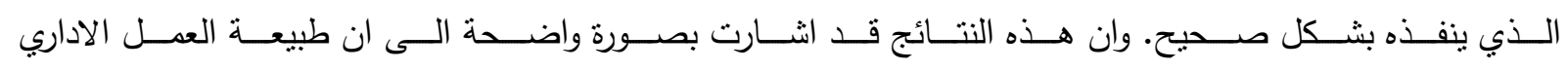

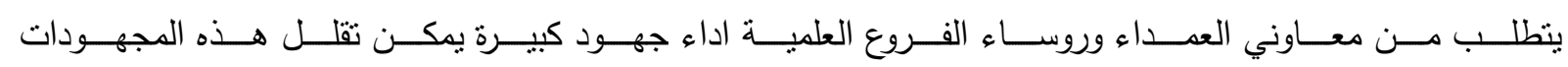

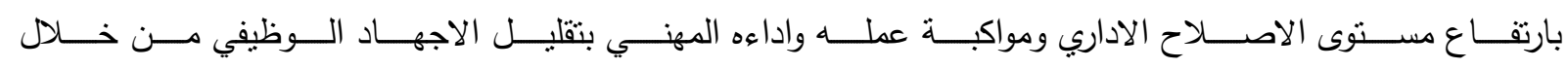

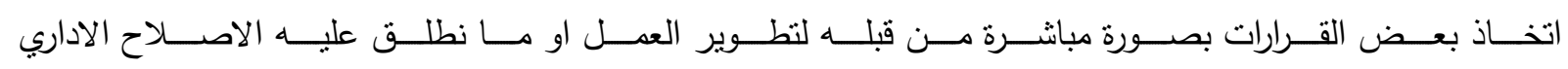

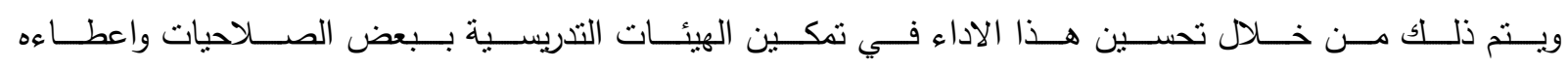

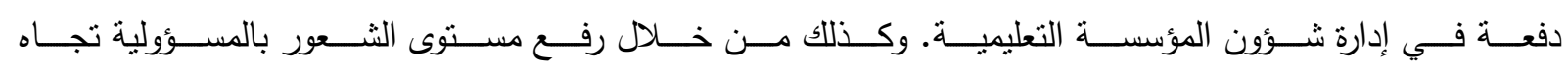

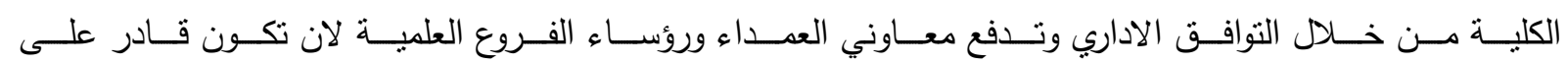




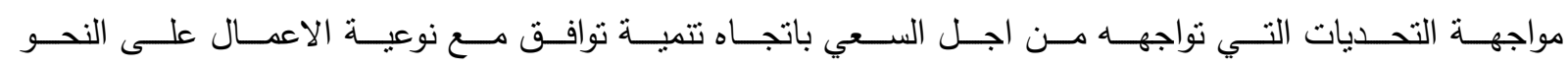

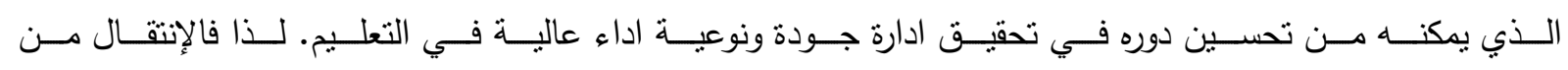

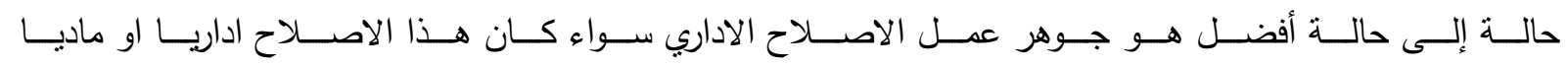

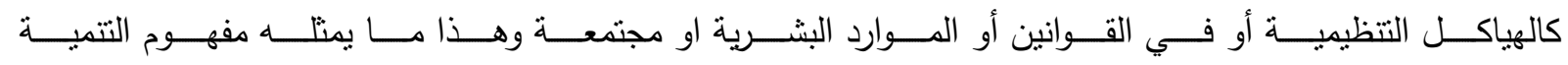

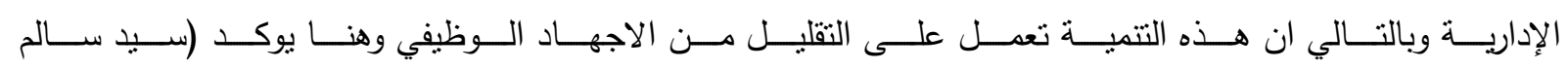

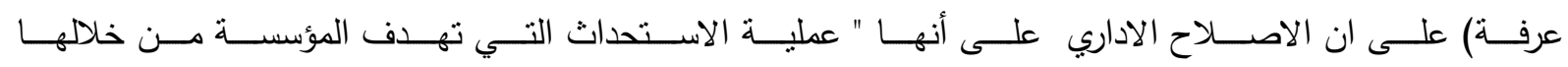

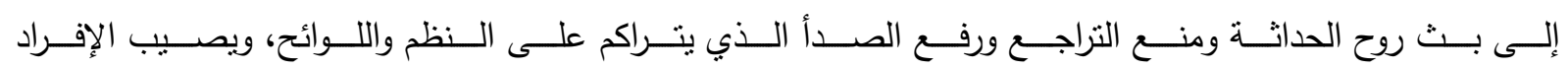

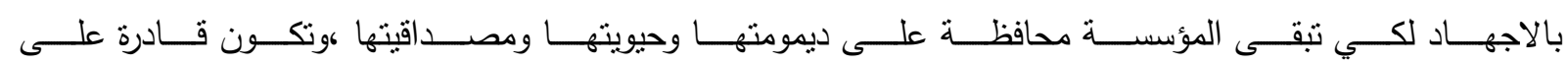
التكيف مع الظروف " لذا ان كفاية النهوض بأعباء الوظيفة ومدى آستعداده لتقلد الموقع الاداري.

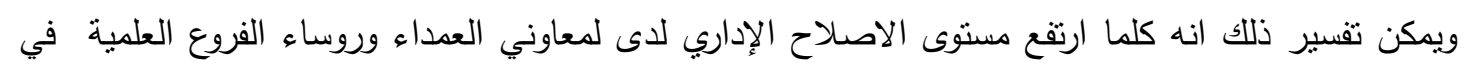

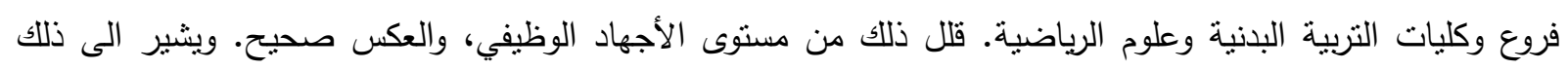
(كمال درويش) الى ان الاداري " هو الفرد الذي يشعر بما يجب عمله وكيفية عمله في أي مستوى تنظيمي، وأنه يقوم

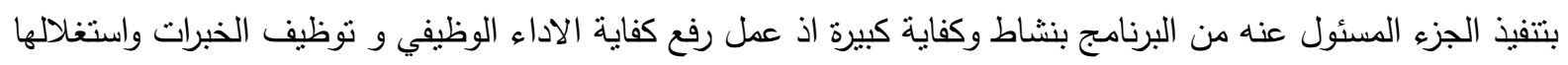

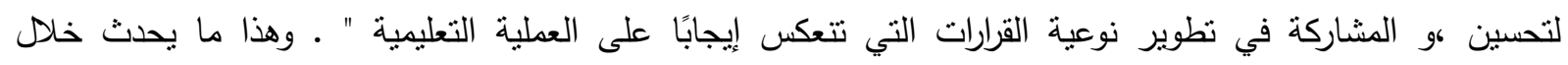
الاصلاح الاداري لذلك كانت النتائج منطقية وتحقق الفرض الاول الذي يشير (توجد علاقة ارتباط معنوي بين الاصدلاح الاداري مع الاجهاد الوظيفي لدى معاوني العدداء ورؤساء الاقسام في أقسام وكليات التربية البدنية وعلوم الرياضية).

\section{المصادر}

احمد راسم عباس(2013). أنماط الثخصية وعلاقتها بمصادر الإجهاد الوظيفي للمحققين الإداريين في مكاتب المفتشين العامين: بحث تطبيقي، دبلوم عالي، كلية الادارة والاقتصاد، جامعة بغداد.

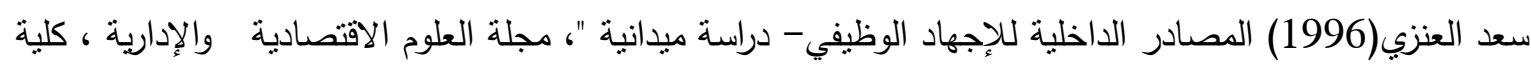

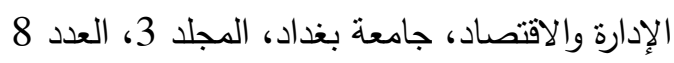

هيد سالم عرفة (2012).اتجاهات حديثة في إدارة التغيير، عمان: دار الرائة الرادية للنشر والتوزيع.

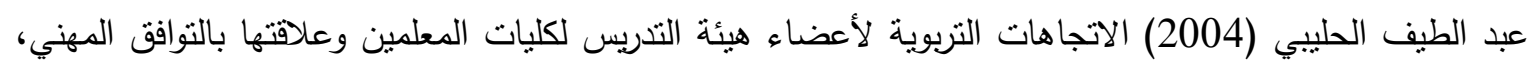
جامعة الملك سعود. كمال درويش (1993) الأسس العلمية للتخطيط والتتظيم والإدارة في مجال التربية الرياضية ، القاهرة: دار الفكر العربي. وجيه محجوب(2002) أصول البحث العلمي ومناهجه، عمان: ط1، دار المناهج للنشر، 

الملاحق

الملحق (1) مقياس الاصدلاح الاداري

\begin{tabular}{|c|c|c|c|c|c|c|}
\hline \multirow[b]{2}{*}{ دائماً } & \multicolumn{5}{|r|}{ 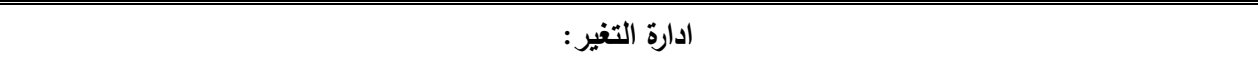 } & \multirow[b]{2}{*}{ 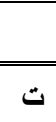 } \\
\hline & غالباً & 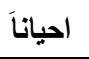 & نادراً & ابداً & العبــــــــارة & \\
\hline & & & & & ان ادارة الكلية تعمل على تغيرات في أهداف وسياسات الإدارة & 1 \\
\hline & & & & & ان ادارة الكلية تساهم في تخفيض تكاليف الانفاق في الكليات والجامعات & 2 \\
\hline & & & & & انشطة الكليات والجامعات من اجل تحلية نظامية تكاملية تعمل على تنسيق و تحسين & 3 \\
\hline & & & & & معرفة جديدة ادارة الكلية ادارة تثجيع القدرات الابداعية و مواردها البشرية لظلق & 4 \\
\hline & & & & & توفر ادارة الكلية على تثجيع استداث أوضاع تنظيمية وأساليب إدارية & 5 \\
\hline & & & & & تعمل على تثلجيع التطلم و اكتساب العاملين في المؤسسات و الهيئات & 6 \\
\hline & & & & & تحقيق الاهداف ادارة الكلية بأستمرار الى اقتراحات الموظفين و الخبراء من اجل & 7 \\
\hline & & & & & تعمل ادارة الكلية تحليل البيئتين الخارجية والداخلية & 8 \\
\hline & & & & & تعل ادارة الكلية إلى بث روح الداثثة ومنع التراجع & 9 \\
\hline & & & & & تعمل ادارة الكلية خطة تطويرية في فترة زمنية محددة & 10 \\
\hline & & & & & تلتزم ادارة الكلية بمعايير الجودة الثاملة & 11 \\
\hline & & & & & 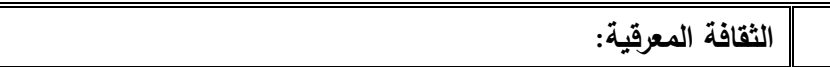 & \\
\hline & & & & & تعمل ادارة الكلية على نقل و توزيع المعرفة من خلال المعرفة المتنوعة & 12 \\
\hline & & & & & تعمل ادارة الكلية اعداد برامج تدريبية للكادر الفني فيها للمثاركة في & 13 \\
\hline & & & & & تعويلها الى مثاريع و الكلية على استثمار جميع المعارف المخزونة سابقاً و & 14 \\
\hline & & & & & 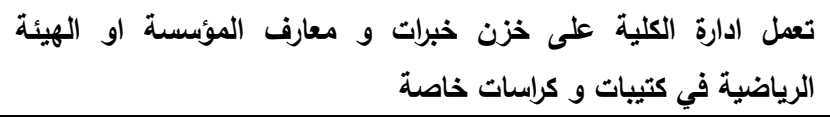 & 15 \\
\hline & & & & & تعلية ادارة الكلية حصر المعارف و الخبرات التي يمتكها التدريسين داخل & 16 \\
\hline & & & & & تعرل ادارة الكلية على نظام داخلي لارشفة المعارف و حفظ و امان و & 17 \\
\hline & & & & & 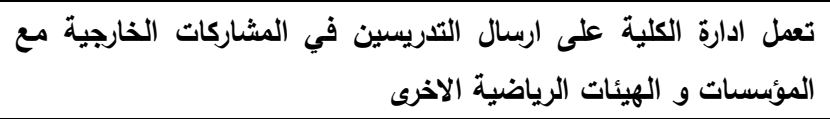 & 18 \\
\hline & & & & & 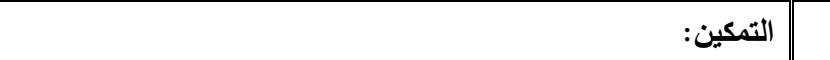 & \\
\hline & & & & & تفوض العمادة او القسم سلطات كافية للتدريسين لانجاز مهام & 19 \\
\hline & & & & & تلتدريسين العمادة او القسم في فرات الترريسين على أداء المهام الموكولة & 20 \\
\hline & & & & & يمارس رؤساء الاقسام الصلاحيات المفوضة إلا خلال فترة التفويض & 21 \\
\hline & & & & & لا تمنح العمادة او القسم المرونة المناسبة للتصرف في أداء مهام & 22 \\
\hline
\end{tabular}


مجلة كلية التربية الرياضية / جامعة بغداد * المجلد الحادي والثلاثون* العدد الثالث * 2019.

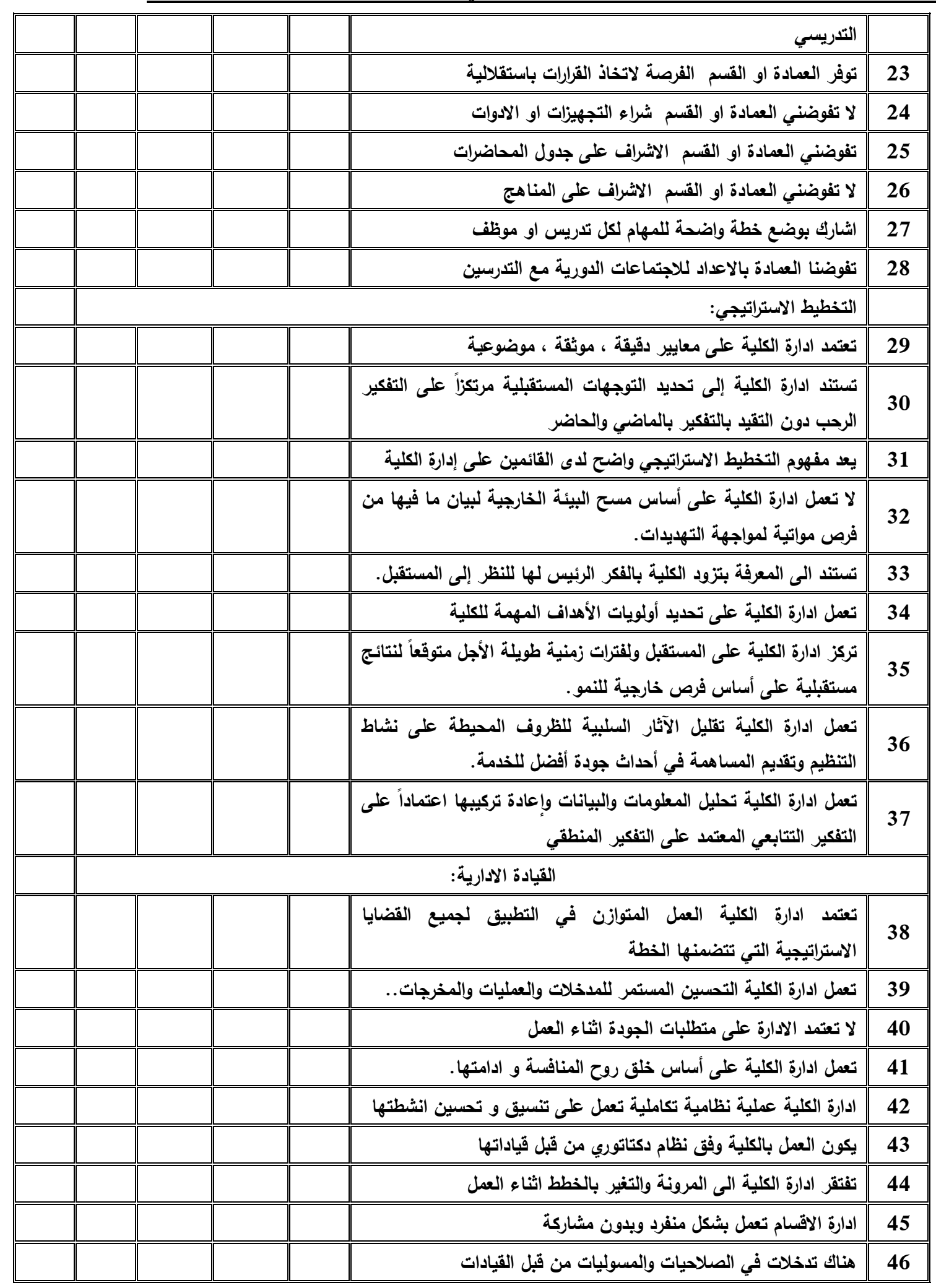


مجلة كلية التربية الرياضية / جامعة بغداد * المجلد الحادي والثلاثون* العدد الثالث * 2019. الملحق (2) مقياس الاجهاد الوظيفي

\begin{tabular}{|c|c|c|c|c|c|c|}
\hline دائماً & غالباً & احياناً & نادراً & ابداً & الفقرة & 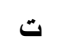 \\
\hline & & \multicolumn{5}{|c|}{ خصائص الدور: } \\
\hline & & & & & أ أعاني من غوض دوري في العمل . & 1 \\
\hline & & & & & | اشعر بالحاجة للوقت لاداء العمل الموكل لي & $\overline{2}$ \\
\hline & & & & & | أعاني من صراع الدور الذي أمارسه في العمل . & 3 \\
\hline & & & & & | اشعر بكمية العمل الملقاة علي اكبر من قدراتي & 4 \\
\hline & & & & & |أعاني من ثقل مهمات الدور المناط بي. & $\overline{\mathbf{5}}$ \\
\hline & & & & & أعاني من قلة مهمات الدور في العمل . & 6 \\
\hline & & & & & أعاني من ضعف دعم الإدارة للاور الذي أمارسه & 7 \\
\hline & & & & & اشعر اني اودي بعض النشاطات بصورة خاطئة & $\overline{88}$ \\
\hline & & \multicolumn{5}{|c|}{ نوعية العمل: } \\
\hline & & & & & ايُعد توزيع الاعمال غير عادل في كليتنا. & 9 \\
\hline & & & & & |قوم باعمال لاتناسب تحصيلي & $\overline{10}$ \\
\hline & & & & & يوجد ضعف في مسؤوليات الوظيفة التي أؤديها. & 11 \\
\hline & & & & & اشعر باستبدادية العلاقة مع المروسين & 12 \\
\hline & & & & & لا أعاني من ضغط الوقت . & 13 \\
\hline & & & & & تعمل ادارة الكلية على كثرة التنقلات & 14 \\
\hline & & & & & 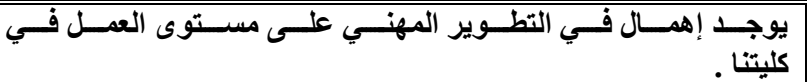 & 15 \\
\hline & & & & & التغير المستمر لنوع المواد الاراسية التي ادرسها & 16 \\
\hline & & & & & لا توجد صعوبة في أهداف العمل الأي أؤديه . . & 17 \\
\hline & & \multicolumn{5}{|r|}{ التنظيم } \\
\hline & & & & & أنتبع المركزية الثشديدة في العمل. & 18 \\
\hline & & & & & هناك ارشادات وسياسات متعارضة & 19 \\
\hline & & & & & تكثز القيود الرسمية في الهيكل التنظيمي. & 20 \\
\hline & & & & & هناكت تداخل السلطات والصلاحيات & 21 \\
\hline & & & & & ي يُتعامل في التخصص الدقيق داخل الكلية & 22 \\
\hline & & & & & كثرة الخلافات بين التّريسين & 23 \\
\hline & & & & & هنالك استقلالية ذاتية في العمل. & 24 \\
\hline & & & & & نعمل لساعات عمل طويلة & 25 \\
\hline & & & & & يوجد نقص في المشاركة في القرار . & 26 \\
\hline & & & & & طرف التواصل و الاتصالات ضعيفة بين الكوادر . & 27 \\
\hline & & & & & يوجل سوء في عدالة تقييم الأداء. . & 28 \\
\hline & & \multicolumn{5}{|c|}{ بيئة العمل: } \\
\hline & & & & & يوجد ضعف في ترتيب المكان الخاص بي. & 29 \\
\hline & & & & & لهنالك ضوضاء عالية في مكان التّريس. & 30 \\
\hline & & & & & | نتعامل مع وجود ظروف عمل غير صحية . & 31 \\
\hline & & & & & توجل مخاطر في الأمان المهني. & 32 \\
\hline & & & & & لتُعل الإضاءة غير كافية في مكان التّريس. & 33 \\
\hline & & & & & | مكان الكلية بعيد عن السكن & 34 \\
\hline & & & & & لاتوجد بيئة ملائمة للعمل & 35 \\
\hline & & \multicolumn{5}{|c|}{ العلاقّات الاجتماعية } \\
\hline & & & & & ليوجد ضعف واضح في علاقات التدريسين. & 36 \\
\hline & & & & & يُعُ التماسكك بين اعضاء التّريسين مفقوداً. & 37 \\
\hline & & & & & يوجد نقص في الدعم الاجتماعي داخل الدائرة. & 38 \\
\hline & & & & & توجد صراعات وخلافات واضحة بين التريسين. & 39 \\
\hline & & & & & يشارك التدريسين في مناسبات الزملاء & 40 \\
\hline
\end{tabular}

